\title{
Influence of Sn doping ratio on the structural and optical properties of CdO films prepared by laser induced plasma
}

\author{
Kadhim A. Aadim ${ }^{1}$, Baida M. Ahmed ${ }^{2}$, Madyan A. Khalaf ${ }^{2}$ \\ ${ }^{1}$ Department of Physics, College of Sciences, University of Baghdad, Iraq \\ ${ }^{2}$ Department of Physics, College of Sciences, University of Mustansiriyah, Iraq \\ E-mail: kadhim_adem@scbaghdad.edu.iq,dr.baida_222@uomustaniriyah.edu.iq
}

Corresponding author: madyan.ahmed1990@gmail.com

\begin{abstract}
In this work, we study the effect of doping Sn on the structural and optical properties of pure cadmium oxide films at different concentrations of Tin (Sn) (X=0.1, 0.3 and 0.5$)$. The films prepared by using the laser-induced plasma at wavelength of laser $1064 \mathrm{~nm}$ and duration 9 ns under pressure reached to $2.5 \times 10-2$ mbar. The results of X-ray diffraction tests showed that the all prepared films are polycrystalline. As for the topography of the films surface, it was measured using AFM, where the results showed that the grain size increases with an increase in the percentage of doping in addition to an increase in the average roughness. The optical properties of all films have also been studied through the absorbance spectrum of the range of the wavelength (350-1100) nm, where the optical energy gap was direct transitions it was found that the value of the optical energy gap increased with increasing the doping This increase can be interpreted as a result of the so-called Borsstein-Moss displacement, because because the lower levels of the conduction beams are full of electrons, the electrons need more energy to travel, so it seems as if the energy gap increases.
\end{abstract}

Key words

Laser Induced Plasma (LIP), thin films, structural properties, optical properties.

Article info.

Received: Feb. 2020

Accepted: Mar. 2020

Published: Jun. 2020

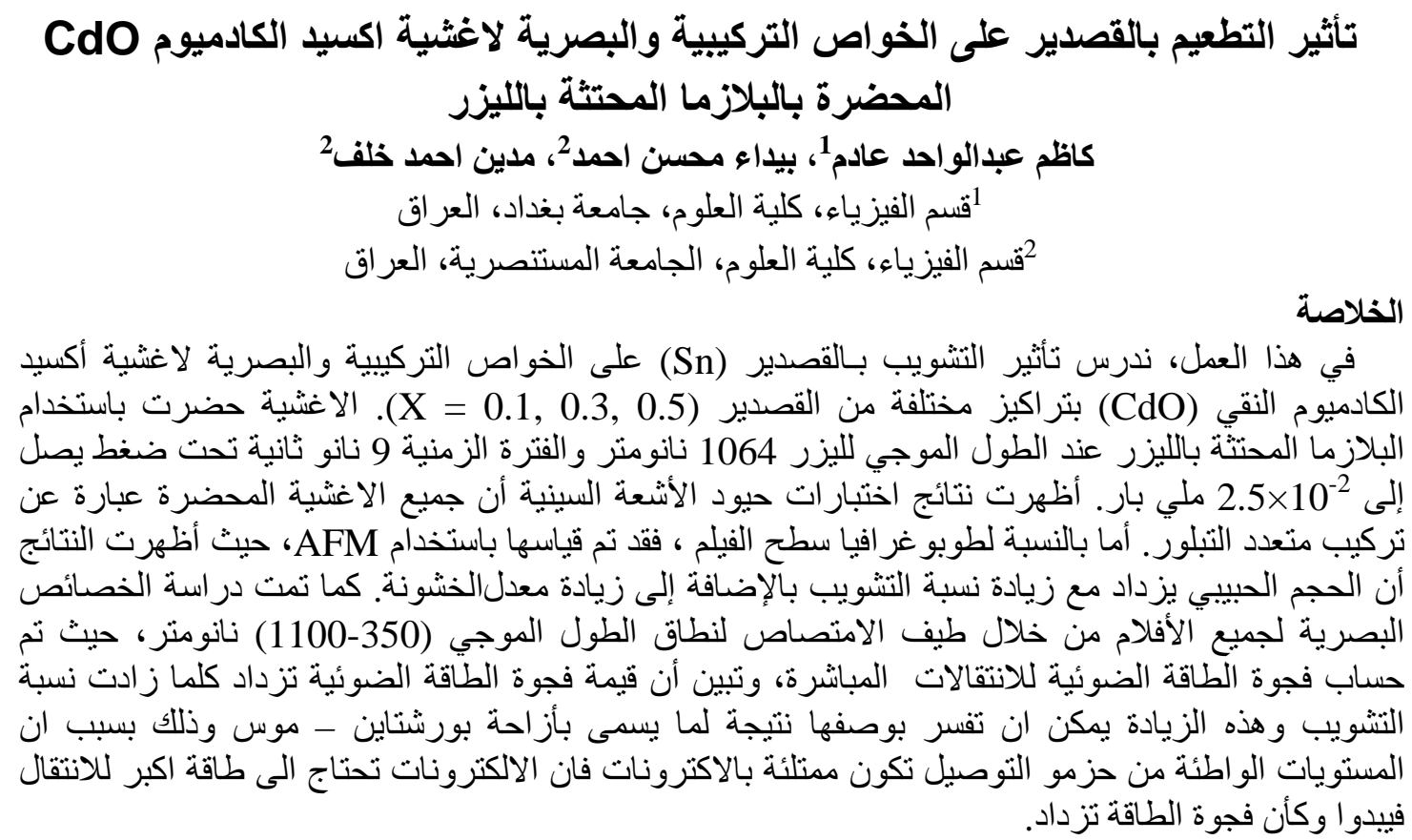




\section{Introduction}

The pulse laser deposition method is one of the best and cheapest techniques for semiconductor and mineral deposits and oxides in different technological conditions. Although the deposition by a pulse laser technology was first used in the manufacture of thin films even in 1960 [1]. Pulse laser deposition (PLD) is usually preferred to use high-energy laser pulses with an energy density of more than $10^{8}\left(\mathrm{~W} / \mathrm{cm}^{2}\right)$ to precipitate a thin layer from one target. As this type of semiconductor material is mostly prepared in the form of thin films [2]. In the primitive part of the pulsed laser the vapor forms a thick layer over the surface of the target material that leads to energy absorption leads to an increase in pressure in addition to the temperature of this vapor, and thus partial ionization will occur. This layer will extend from the target surface, due to the high pressure. This is called plasma plum [3]. Thin films of conductive oxide (TCO), such as cadmium oxide, zinc oxide, Tin oxide, copper oxide is highly regarded due to its high optical transmittance and low resistance [4]. In particular there is an interest in $\mathrm{CdO}$ due to its low resistance and high carrier concentration, which makes it have great potential for use in optical electronic devices [5].

\section{Experiment part}

In this experiments, Thin films were prepared by a pulsed laser deposition technique where pulses were directed from a Nd:YAG laser with a wavelength of $1064 \mathrm{~nm}$, frequency of 6 $\mathrm{Hz}$ and duration $9 \mathrm{~ns}$ with $\mathrm{E}=500 \mathrm{~mJ}$ under vacuum $2.5 \times 10^{-2}$ mbar. The experimental arrangement of (PLD) as shown in Fig.1.

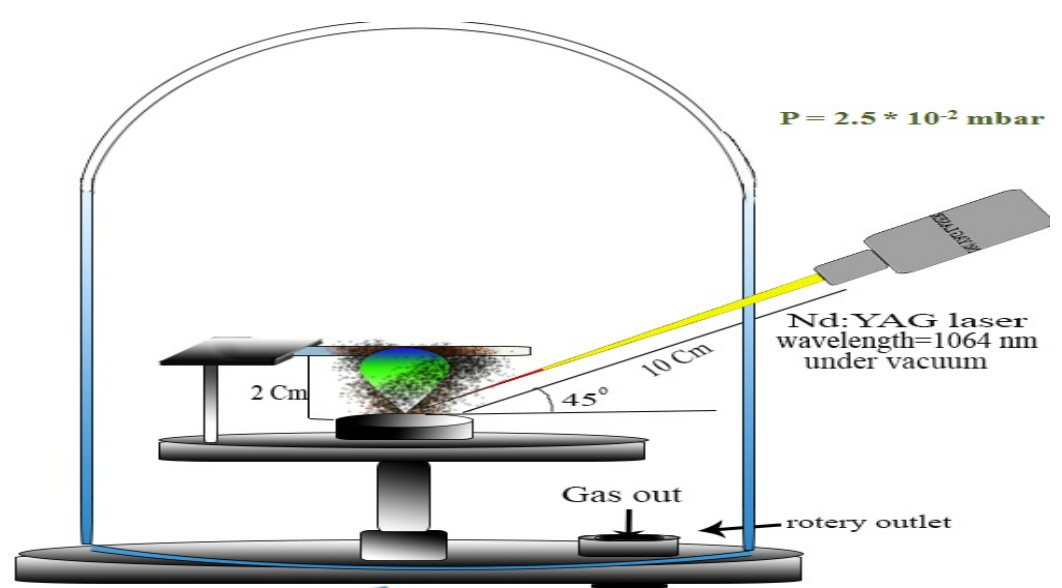

Fig. 1: Illustration of the PLD system used in this work.

The pulse energy and size of the laser spot changing by the distance between the laser lens and the target, all are controllable and the number of pulses is also possible to be controlled and variable. The laser beam was focused on the target makes an angle of $45^{\circ}$ with the laser beam. 3 gm of target material, which is $\mathrm{CdO}$ and $\mathrm{CdO}_{1-\mathrm{X}}$ : $\mathrm{Sn}_{\mathrm{X}}$ at $(\mathrm{X}=0.1,0.3,0.5)$ was pressed using the hydraulic piston under a pressure of 6.8 bar, to obtain disc with thickness of $4.0 \mathrm{~cm}$ and $1 \mathrm{~cm}$ in diameter. The crystal structure of all films was analyzed using an X-ray diffraction device and X-ray emitter type $\mathrm{Cu}(\mathrm{k} \alpha)$, wavelength $=1.5418 \mathrm{~A}^{0}$, energy $=30 \mathrm{kV}$, current $=10 \mathrm{~mA}$. Atomic force microscopy (AFM) was employed to study the morphological characteristics of the nano films prepared by PLD technique on a glass 
slide. UV - Visible spectrophotometer was used within the wavelength range (350-1100) $\mathrm{nm}$ to calculate the optical properties of thin films.

\section{Results and discussion}

\section{X-ray diffraction examination}

The results of the diagnosis using $\mathrm{X}$-ray diffraction technique showed that all prepared thin films with polycrystalline. It can be seen that the CdO pure film is polycrystalline with peaks appear at $2 \theta=33.0088^{\circ}, 38.306^{\circ}$, $55.2902^{\circ}, 65.9186^{\circ}$ and $69.2498^{\circ}$ belong to hkl [(111), (200), (220), (300) and
(222)] and contains a cubic crystal structure with a preferred orientation along (111) plane. Which identical with JCPDS card No. (39-1221). As for Fig.2, show the X-ray diffraction of the $\mathrm{CdO}, \quad \mathrm{CdO}_{1-\mathrm{X}}: \mathrm{Sn}_{\mathrm{X}}$ thin films of thickness of $200 \mathrm{~nm}$, where we notice that when increasing the rate of doping led to a decrease in the intensity of the peaks, in addition to shifting the angles to the larger $2 \theta$ values, and increasing doping led to an increase in crystallization this agreement with Zhao (2002) [6].

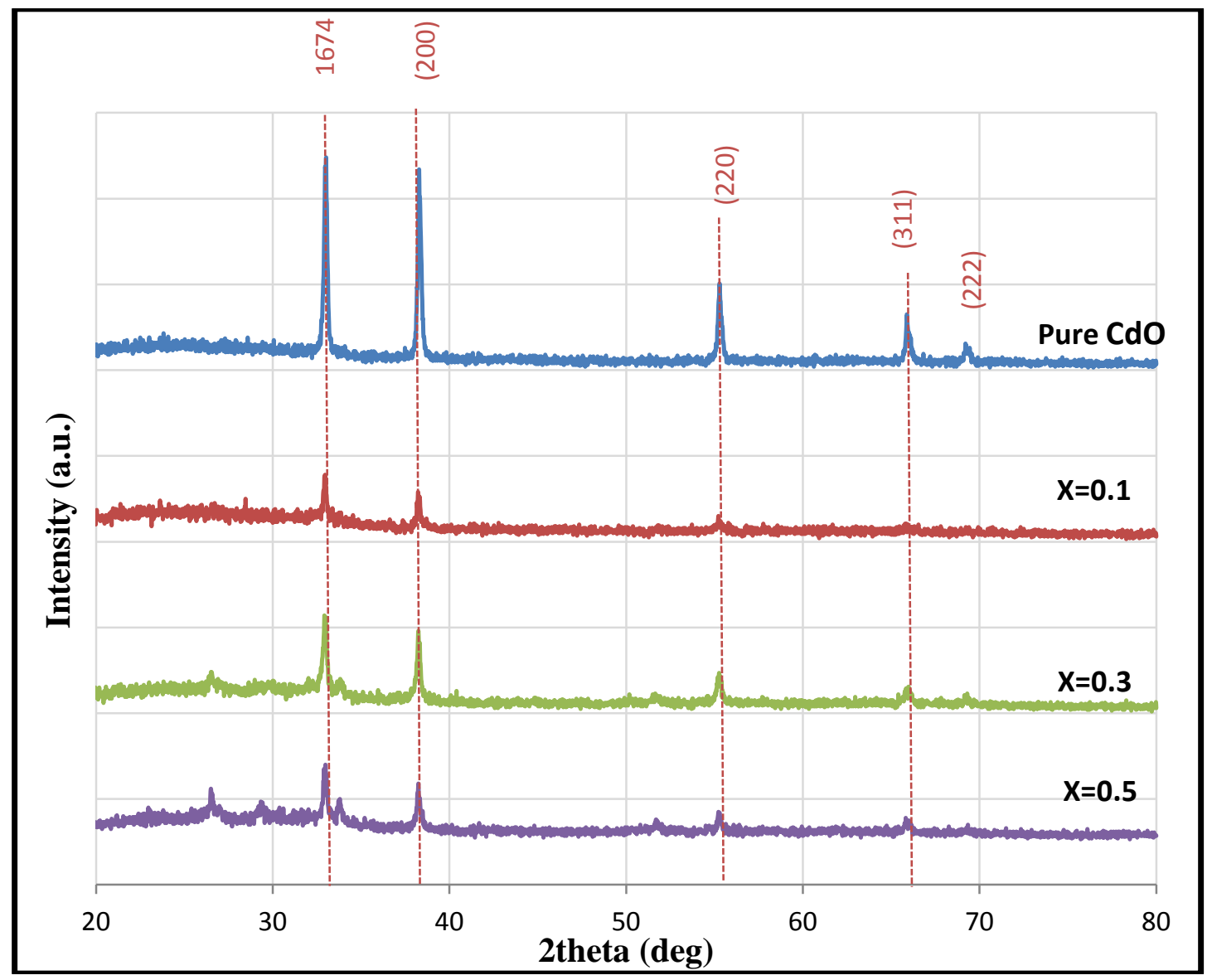

Fig. 2: XRD pattern for $\mathrm{CdO}$ and $\mathrm{CdO}_{1-X}: \mathrm{Sn}_{X}$ thin films prepared at different ratio.

\section{Atomic Force Microscope} measurements (AFM)

Topography of deposit surfaces has been studied using an atomic force microscope. Fig.3 shows images (AFM) of pure CdO films and with different Sn doped. 

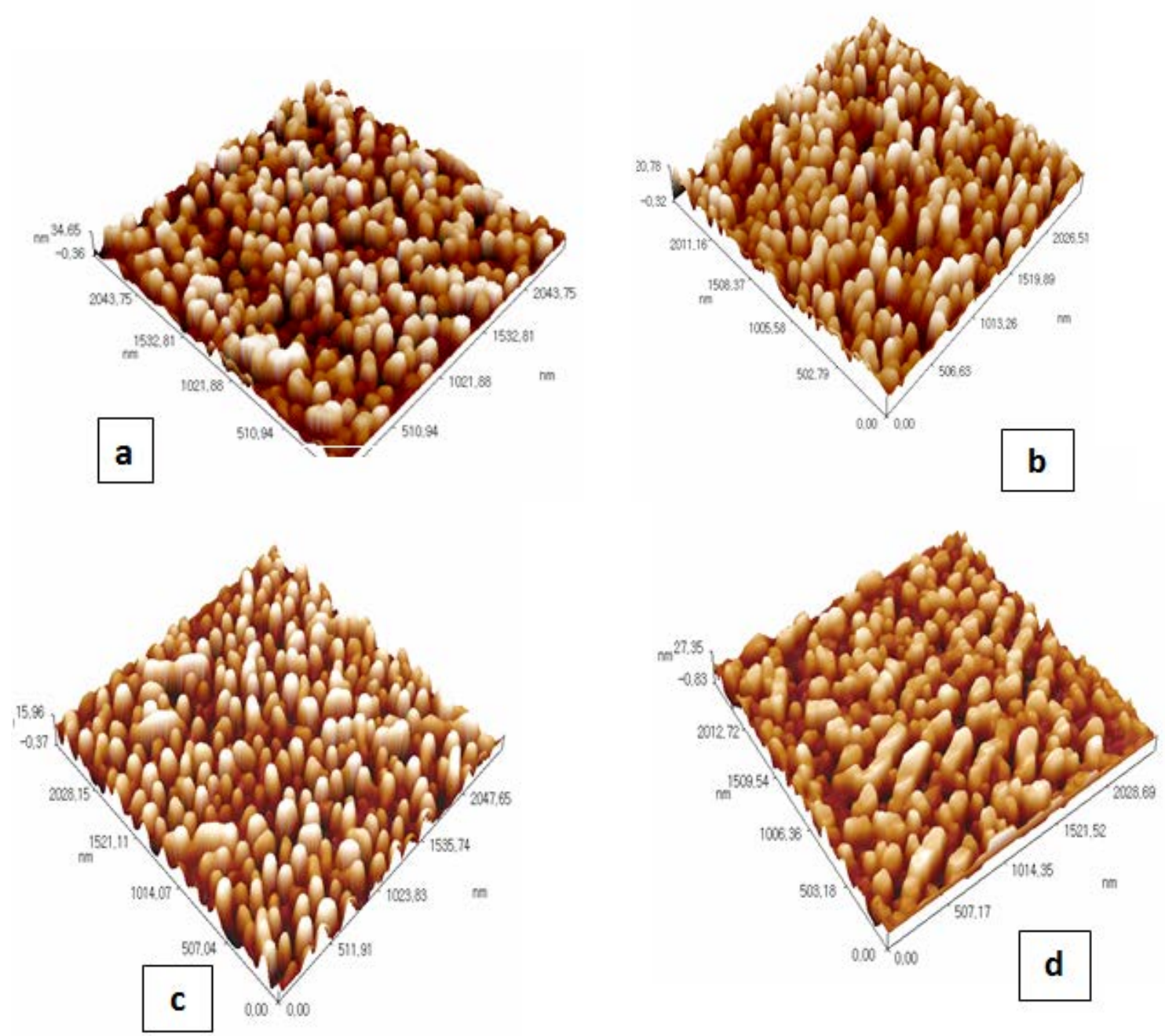

Fig.3: AFM images of CdO:Sn thin films deposited with different Sn concentration: (a) pure CdO, (b) 0.1, (c) 0.3 and (d) 0.5 .

Table 1 AFM parameters (average diameter, Root mean Square and average roughness) for $\mathrm{CdO}_{1-\mathrm{X}}: \mathrm{Sn}_{\mathrm{X}}$ thin films $(X=0.1,0.3,0.5)$ thin films deposited by pulses laser on the glass substrate.

Table 1: AFM parameters (Grain size, RMS and Average Roughness) for $\mathrm{CdO}_{1-\mathrm{X}}: \mathrm{Sn}_{X}$ thin films at different ratio.

\begin{tabular}{|c|c|c|c|}
\hline sample & Grain Size (nm) & $\begin{array}{c}\text { Root Mean Square } \\
(\mathrm{RMS})(\mathbf{n m})\end{array}$ & $\begin{array}{c}\text { Average Roughness } \\
(\mathbf{n m})\end{array}$ \\
\hline CdO & 68.14 & 2.86 & 2.08 \\
\hline $\mathrm{X}=0.1$ & 73.02 & 5.17 & 4.35 \\
\hline $\mathrm{X}=0.3$ & 78.01 & 6.29 & 5.27 \\
\hline $\mathrm{X}=0.5$ & 86.02 & 10.1 & 8.75 \\
\hline
\end{tabular}

It is noted through the above table that the grain size and the roughness average, in addition RMS increasing, as the tin doping increases. 
Optical properties measurements

\section{Absorption spectrum}

Absorption measurements have been made within the wavelength range (350-1100) nm of all pure and tindoped CdO films with different doping ratios. Fig. 4 shows a change in the absorption spectrum as a function of the wavelength since the absorbance of all the films is the greatest possible at the primary absorption edge (short wavelengths), the prepared films are characterized by high absorbance at short wavelengths, and we note that they are located within the visible region and thus can be used in solar cell applications, and absorption decrease with increase doping this agreement with de León-Gutiérrez (2006) [7].

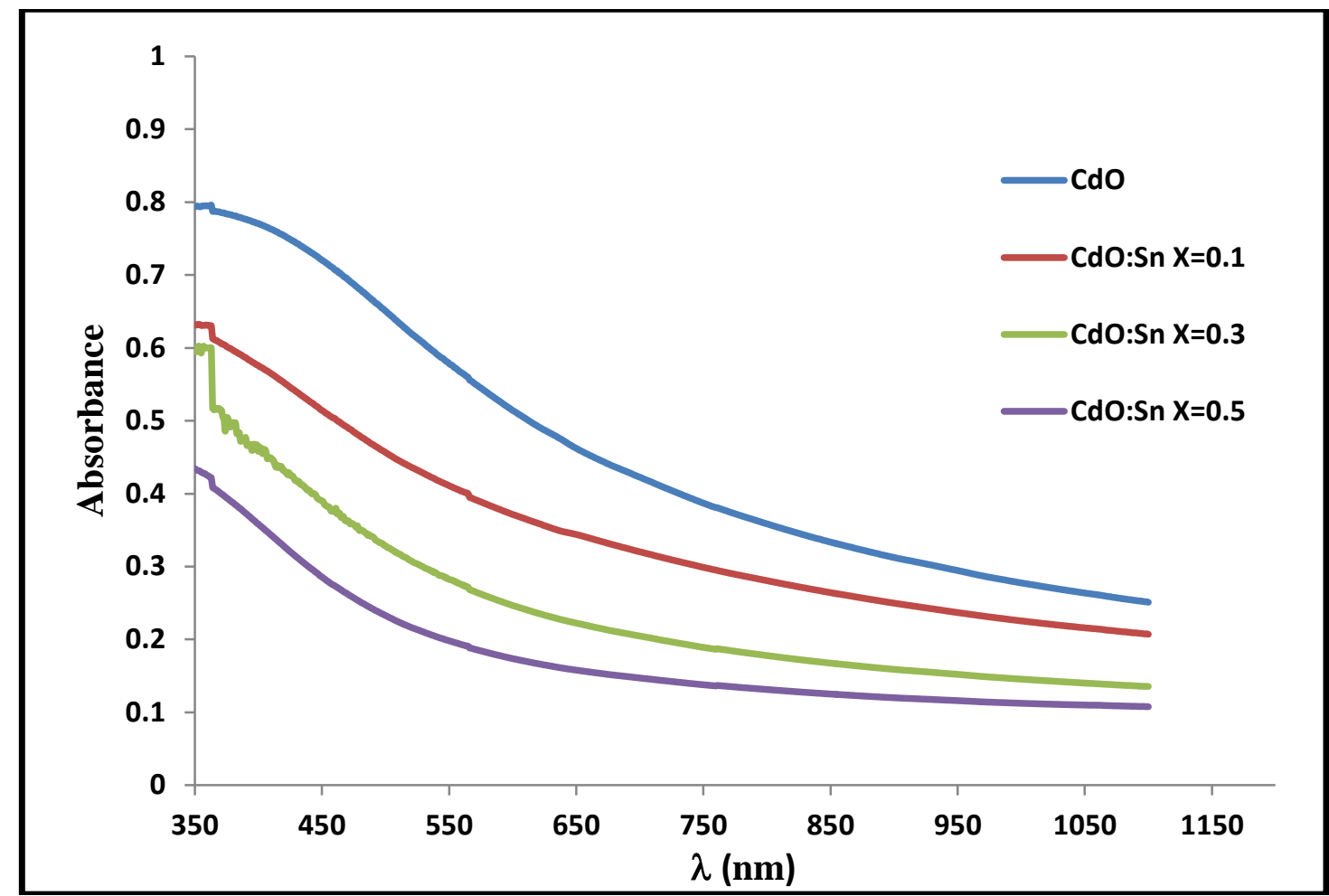

Fig. 4: The variation of absorbance with wavelength for $\mathrm{CdO}_{1-\mathrm{X}}: \mathrm{Sn}_{X}$ thin films deposited on glass substrate.

\section{The absorption coefficient}

The absorption coefficient was calculated from the relationship (1) [8]. Fig.5 shows the change of the absorption coefficient $(\alpha)$ as a function of the wavelength of all films of pure cadmium oxide and doped with tin, we notice from Fig. 5 that the absorption coefficient at these wavelengths has a value greater than $10^{4} \mathrm{~cm}^{-1}$ which is likely to the allowed direct electronic transfers. The absorption coefficient decreases with increasing percentage of doping. These results are found in agreement with the Kathalingam (2018) [9].

$\alpha=\frac{2.303 A}{\lambda}$

where $\lambda$ is a wavelength, $\mathrm{A}$ : is the absorption. 


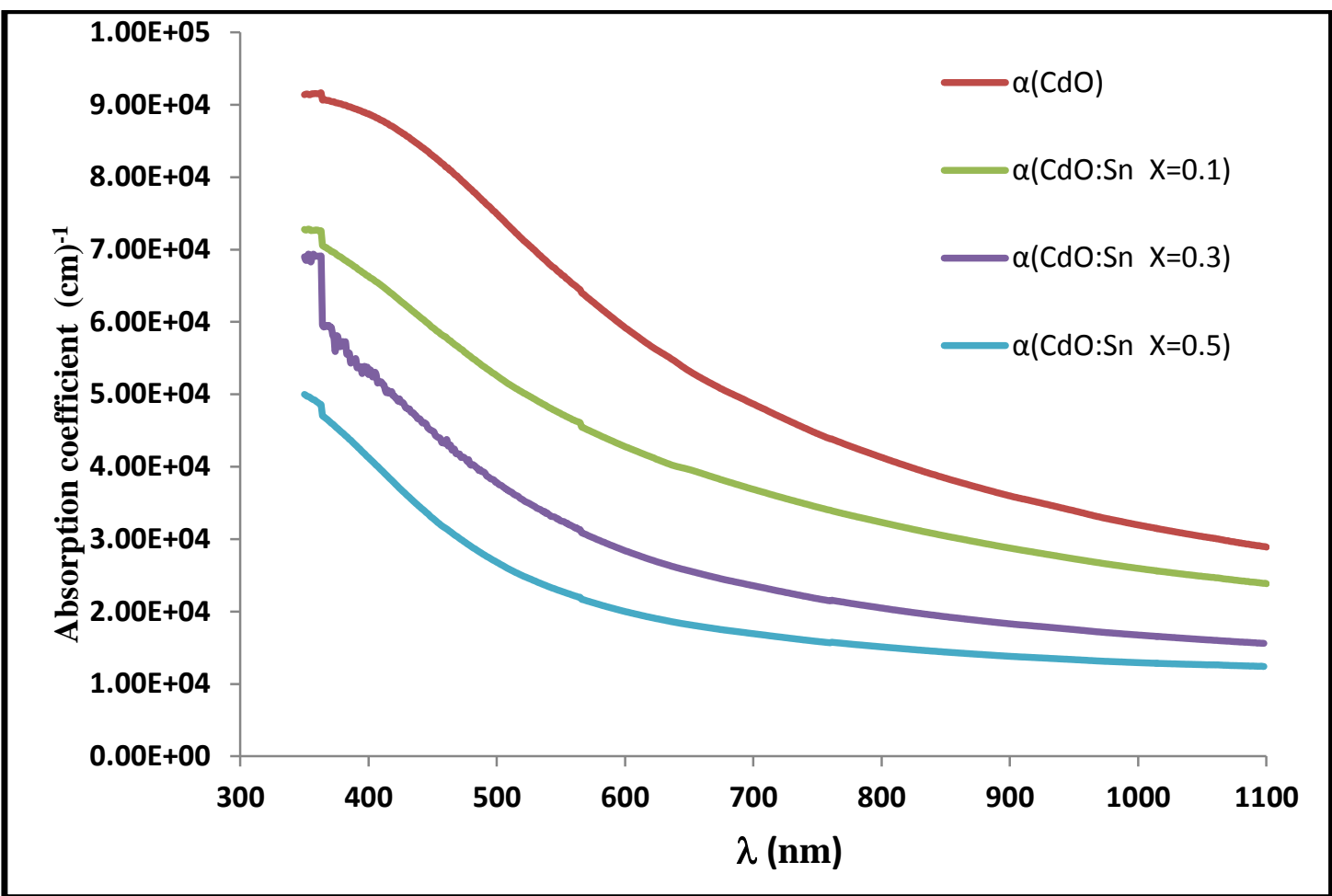

Fig. 5: Variation of absorption coefficient as a function of wavelength for pure CdO and $\mathrm{CdO}_{1-\mathrm{X}}: \mathrm{Sn}_{X}(\mathrm{X}=0.1,0.3$ and 0.5$)$.

\section{Calculation of the optical energy} gap $\left(E_{g}\right)$

The optical energy gap of allowed direct electronic transitions for all thin films has been calculated using Tauc Eq.(2) [10] as the value of $r=1 / 2$ by drawing the linear relationship between $(\alpha h v)^{2}$ and (hv) the energy of the falling photon and by extending the straight line of the curve to cross the photon energy axis at the point $(\alpha h v)^{2}=0$. Fig. 6 shows the optical energy gap for permissible direct transport of tindissolving cadmium oxide films. Fig.6 shows the optical energy gap for allowable direct transport of tin-doping cadmium oxide films. From the Fig. 6 it was observed that the increase in the cadmium oxide doping led to the increase in the optical energy gap values and for all the doping ratios. This means that the doping led to the displacement of the absorption edge towards high energies and this increase can be interpreted as a consequence of what is called (Bureshtain-Moss Shift), this is because the levels near the conduction beam are full of electrons, so the electrons need more energy to travel, so it seems as if the energy gap increases These results are found in agreement with the Zheng (2011) [11]. Table 2 shows the energy gap values for all thin films.

$\mathrm{ahn}=\mathrm{A}\left(\mathrm{hn}-\mathrm{E}_{\mathrm{g}}\right)^{\mathbf{r}}$ 


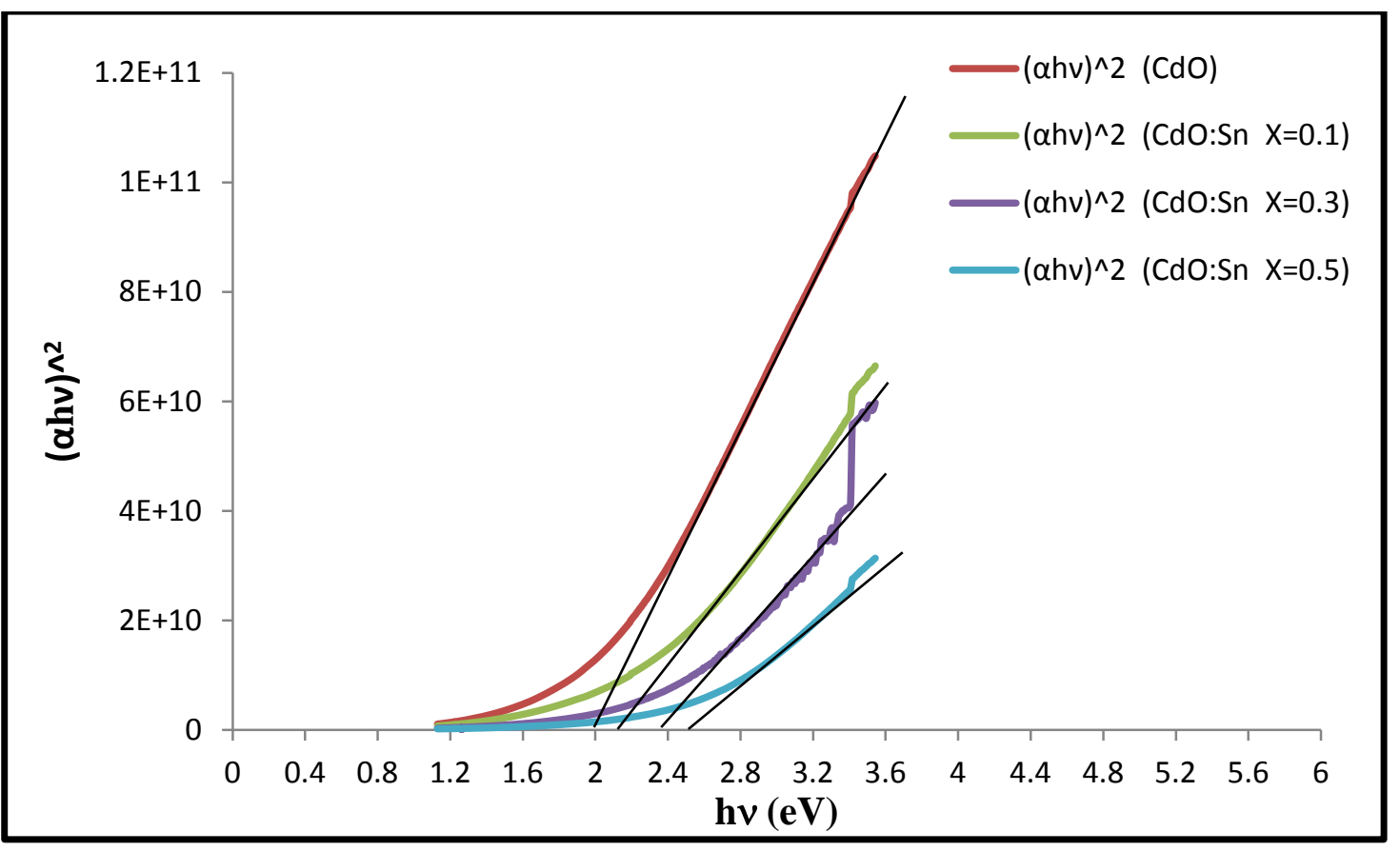

Fig. 6 : The variation of $(\alpha h v)^{2}$ versus photon energy (hv) for $\mathrm{CdO}$ and $\mathrm{CdO} \mathrm{O}_{1-\mathrm{X}}: \mathrm{Sn}_{X}$ thin films deposited on glass substrate.

Table 2: The energy gap of $\mathrm{CdO}$ pure and $\mathrm{CdO}_{1^{-} \mathrm{x}}: \mathrm{Sn}_{x}$ for $(X=0.1,0.3 .0 .5)$ deposited.

\begin{tabular}{|c|c|}
\hline Sample & $\mathbf{E}_{\mathrm{g}}(\mathrm{eV})$ \\
\hline $\mathbf{C d O}$ & 2 \\
\hline $\mathbf{X}=\mathbf{0 . 1}$ & 2.09 \\
\hline $\mathbf{X}=\mathbf{0 . 3}$ & 2.38 \\
\hline $\mathbf{X}=\mathbf{0 . 5}$ & 2.55 \\
\hline
\end{tabular}

\section{Extinction coefficient (k)}

The extinction coefficient was calculated using Eq.3 [12]. Fig.7 shows the extinction coefficient change as a function of the wavelength of all the thin films. It is clear from Eq.(3) that the extinction coefficient depends main on absorption coefficient, i.e. exhibiting the same behavior

$$
k=\frac{\alpha \lambda}{4 \pi}
$$

where $\lambda$ : is a wavelength and $\alpha$ : is the absorption coefficient. 


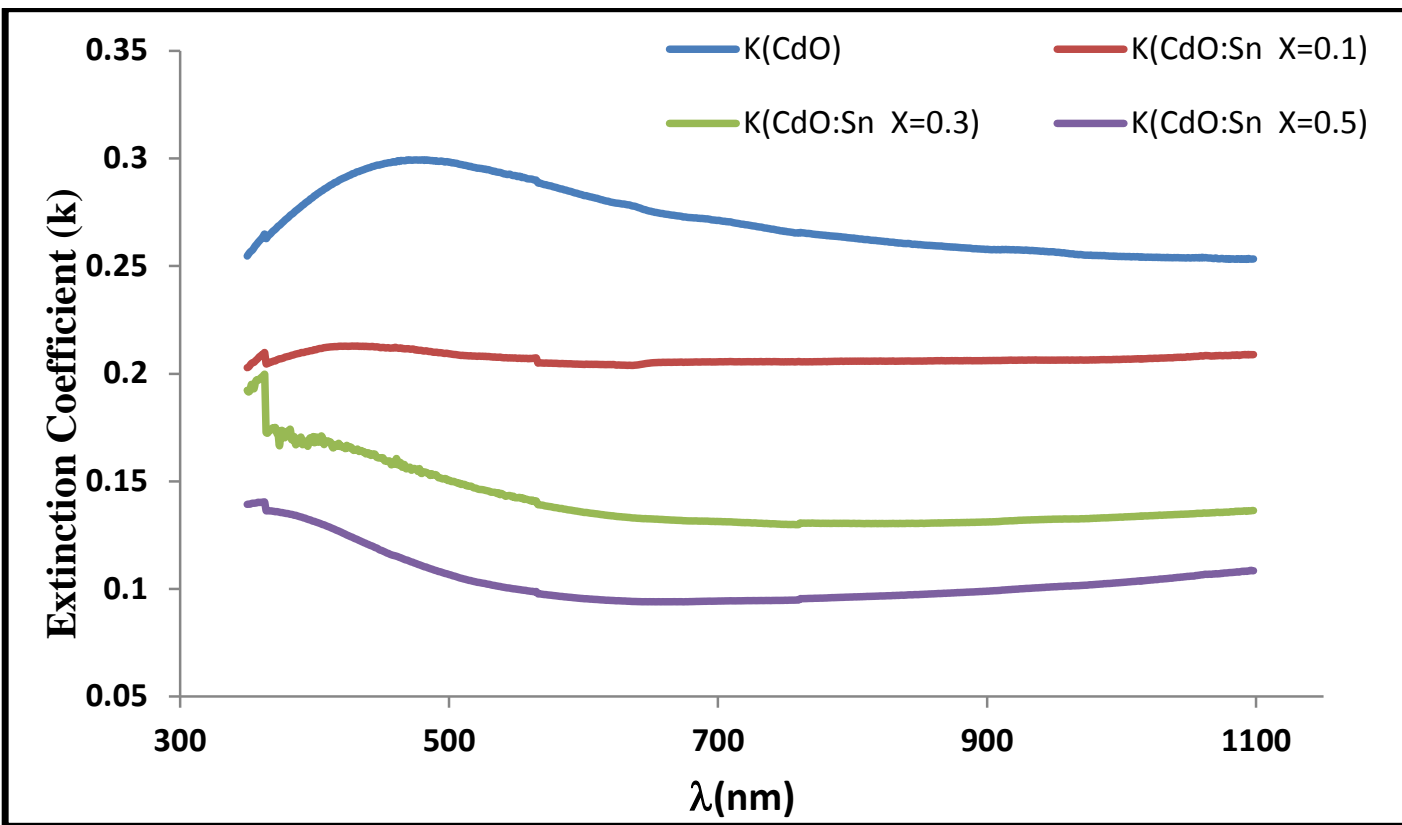

Fig. 7: Variation of extinction coefficient with wavelength for $\mathrm{CdO}$ and $\mathrm{CdO}_{1-X}: \mathrm{Sn}_{X}$ films.

\section{Conclusions}

Nd:YAG laser with fundamental wavelength $1064 \mathrm{~nm}$ was used to prepare film of $\mathrm{CdO}_{1-\mathrm{x}}: \mathrm{Sn}_{\mathrm{X}}$ on the glass substrate:

1- X-ray results showed that all thin films were polycrystalline and have a cubic structure with the dominance of direction (111).

2- The results of AFM show an increase in grain size, the higher the percentage of doping.

3- As for the properties measurements, it was found that the absorption spectrum decreases as the percentage of doping increases, whereas the energy gap, on the other hand, increases with the rate of doping increases.

\section{References}

[1]M. N. R. Ashfold, F. Claeyssens, G. M. Fuge, S. J. Henley, Chemical Society Reviwes, 33 (2004) 23-31.

[2] M. Gunasekara, and M. Ichimura, Japanese Journal nanocrystals, 376 (2011) 659- 663.

[3]R. Eason, "Pulse Laser Deposition of Thin Films", University of Southampton, UKA John Wiley \& Sons, INC., 2007.
[4]S. Aksoy, Y. Caglar, S. Ilican, M. Caglar, International Journal of Hydrogen Energy, 34, 12 (2009) 51915195.

[5] M. Yan, M. Lane, C. R. Kannewurf, R. P. H. Chang, AIP Applied Physics Letters, 78, 16 (2001) 2342-2344.

[6]Z. Zhao, D.L. Morel, C.S. Ferekides, Thin Solid Films, 413 (2002) 203-211

[7]L.R. de León-Gutiérrez, J.J. Cayente-Romero, J.M. Peza-Tapia, E.Barrera-Calva J.C. Martínez-Flores, M. Ortega-López, Materials Letters, 60 (2006) 3866-3870.

[8]A. K. Taki, Diyala Journal of Pure Sciences, 10, 2 (2014) 29-38.

[9]A. Kathalingam, K. Kesavan, Abdul Hassan Sarwar Rana, Joonhyeon Jeon and Hyun-Seok Kim, Coatings, 8, 167 (2018) 1-15.

[10] J.Tauc,"Amorphous and Liquid Semiconductors", Plenum Press London and New York 1974.

[11] B.J. Zheng, J.S. Lian and L. Zhao, Q. Jiang. Vacuum, 85 (2011) 861-865.

[12] R. chauhan, A. k. Srivastava, M. mishra, K. K. Srivastava, Integrated Ferroelectrics, 119 (2010) 22-32. 